oacir Rufino de Aquino

Mestrando do Curso de Mestrado em Economia Rural e Regional.

E-mail: joaciraquino@bol.com.br.

Robério Ferreira dos Santos

Doutor em Economia. Pesquisador da EMBRAPA/CNPA e professor do Curso de Mestrado em Economia Rural e Regional da UFCG.

E-mail:roberio@cnpa.embrapa.br.

\title{
NOVOS DESAFIOS PARA O DESENVOLVIMENTO SUSTENTÁVEL DA AGRICULTURA FAMILIAR NORDESTINA
}

\section{RESUMO}

O objetivo central deste trabalho é analisar, com base em uma pesquisa bibliográfica, qual o papel da agricultura familiar e das políticas de desenvolvimento local para o desenvolvimento sustentável da região Nordeste. Chega-se à conclusão principal de que, através da cooperação entre diferentes segmentos da sociedade, e não através de políticas elaboradas "de cima para baixo" mas, sim, "de baixo para cima", priorizando as potencialidades locais, pode-se encontrar saídas para os vários problemas que caracterizam o espaço rural brasileiro, de modo geral, e o espaço rural nordestino, de modo particular.

Palavras-chave: atividades não-agrícolas; políticas de desenvolvimento local; meio rural do Nordeste brasileiro.

\section{ABSTRACT}

The main objective of this paper is to analyze, based on a bibliographical research, the role of family agriculture and policies of local development on the sustainable development of Brazilian Northeast region. We have reached the main conclusion, that only through the cooperation among different segments of society, giving priority to the local potentialities and not through the policies formulated "from the top down", can we find answers to the many problems faced by the Brazilian rural space in general and the Northeast rural space in particular.

Key words: non-agricultural activities; local development policies; Brazilian Northeast rural field.

\section{INTRODUÇÃO}

A modernização da agricultura brasileira, implantada com base na "via prussiana", trouxe implícito o componente de diferenciação, em que o enriquecimento de algumas regiões aprofunda a decadência de outras, porque as desigualdades não se distribuem de forma homogênea, sendo a região Nordeste o caso mais gritante deste movimento. Insuficiência de terras, de tecnologia e de crédito, comandam o declínio da produção familiar da maior parte dos agricultores nordestinos.

Mais de $50 \%$ da pobreza rural brasileira estão localizados no Nordeste. É nesta região onde se encontra o maior percentual de agricultores familiares descapitalizados do país, vivendo com uma renda monetária oriunda das atividades agropecuárias, em torno de $\mathrm{R} \$ 54,00$ ao ano (INCRA/FAO, 2000). Tal situação amplia a exclusão so- cial e provoca, além disso, maior pressão sobre a base de recursos naturais, como meio de aumentar a produção e melhorar o nível de vida, o que agrava e compromete o meio ambiente regional. Uma prova disso são os altos índices de desertificação apresentados na região; por outro lado, a maior parte das políticas públicas, elaboradas "de cima para baixo", apresenta, na sua grande maioria, caráter puramente setorial, na forma de "pacotes", sendo inviáveis para a realidade local, o que compromete os seus resultados.

Um conjunto de indagações vem à tona. Que políticas devem ser priorizadas para criar um modelo de desenvolvimento sustentável no Nordeste brasileiro? Qual o papel da agricultura familiar neste contexto? Qual o papel da iniciativa local neste movimento?

O objetivo central deste trabalho é analisar, com base em uma pesquisa bibliográfica, qual o papel da agricul-

Raízes, Campina Grande, vol. 21, nº 01, p. 137-147, jan./jun. 2002 
tura familiar e das políticas de desenvolvimento local para o desenvolvimento sustentável da região Nordeste, junto aos novos desafios apresentados no meio rural brasileiro, como o crescimento de atividades não-agrícolas, que se tem apresentado como fontes alternativas de geração de emprego e renda no meio rural nordestino.

Buscar-se-á analisar, inicialmente, alguns efeitos da modernização da agricultura brasileira; em seguida, discutir-se-á a noção de desenvolvimento sustentável, bem como, o papel socioeconômico da agricultura familiar no Nordeste; por último, serão enfatizados a importância da questão local e o seu papel para o desenvolvimento rural nordestino.

\section{ALGUMAS CONSIDERAÇÕES SOBRE A MODERNIZAÇÃO DA AGRICULTURA BRASILEIRA}

O processo de modernização da agricultura brasileira foi iniciado a partir do pós-guerra e consolidou-se com a instalação do setor de produção de bens de capital $\left(\mathrm{D}_{\mathrm{I}}\right)$ para a agricultura, em meados da década de 60. O Estado pode ser destacado como o grande agente protagonista deste movimento modernizador, através da concessão de recursos para a instalação e consolidação da industrialização no campo. As políticas públicas passaram a ser direcionadas para facilitar o processo de acumulação de capital na agricultura. Estas políticas tiveram, como base, o crédito rural de custeio e investimentos, com taxas de juros reais negativas, além de longos prazos de carência. A maior parte desses investimentos foi destinada aos grandes e médios produtores ${ }^{1}$, transformando a terra em um ativo rentável para a mobilização de capital, tanto como forma de angariar recursos como com fins especulativos. Cabe mencionar, ainda, que este processo se caracterizou de forma extremamente desigual e excludente, porque:
A distribuição social, setorial e espacial dos incentivos provocou uma divisão do trabalho crescente; grosso modo, maiores propriedades, em terras melhores, tiveram acesso a crédito, subsídios, pesquisa, tecnologia e assistência técnica, a fim de produzir para o mercado externo ou para a agroindústria. Enquanto isso, os produtores menos capitalizados foram relegados a terras menos férteis, utilizando práticas tradicionais e explorando mão-de-obra familiar para subsistir ou produzir um pequeno excedente comercializado nos mercados urbanos, onde o baixo poder de compra das massas garantiam [e garantem] preços também baixos².

Tais circunstâncias contribuíram para ampliar a concentração fundiária e de renda, ampliando as disparidades sociais no campo entre as diferentes regiões do país. No caso do Nordeste, as disparidades econômicas, sociais e ambientais do atual modelo de desenvolvimento na região, refletem bem esta realidade.

Foi neste cenário que as políticas agrícolas para o campo se desenvolveram. Daí, Santos $(1986)^{3}$ afirmar que existe a presença de vieses no processo de modernização da agricultura brasileira, porque o modelo de desenvolvimento adotado no Brasil foi direcionado para alguns setores, em função do caráter "capitalista” do Estado, atuando como "gerente" do processo de acumulação capitalista no campo. Melhor dizendo, o Estado não é neutro nem exterior às classes sociais, como defenderam os teóricos neoclássicos que elaboraram e consolidaram o processo de modernização da agricultura brasileira. Por isso, na medida em que o Estado é apropriado e desapropriado por diferentes grupos de interesse, ocorre a presença do "viés".

No caso do Brasil, como comenta Santos (1999: 1)4:

Esse modelo de desenvolvimento agrário imposto ao país, limitou o acesso à terra e o desenvolvimento de aproximadamente 5 milhões de pequenos estabelecimentos rurais, ocupados por trabalhadores rurais que vivem em regime de economia familiar.

\footnotetext{
${ }^{1}$ Segundo Belik, W, Estado, grupos de interesse e formulação de políticas para a agropecuária brasileira, Rev. Econ. Sociol. Rural, v. 36, n. 1, p.9-34, jan/mar. 1998, "Em termos de distribuição do crédito, o Censo de 1980 aponta que $80 \%$ dos estabelecimentos agrícolas não recebiam qualquer crédito, mas que apenas $1 \%$ dos estabelecimentos que produziam apenas $15 \%$ do total e empregavam 3\% da mão-de-obra, recebeu $40 \%$ dos recursos".

${ }^{2}$ MARTINE, G., Fases e faces da modernização agrícola brasileira, Planejamento e Políticas Públicas, v. 1, n⿳0 3, p. 3-44, jun. 1990.

${ }^{3}$ SANTOS, R. F. dos, Análise crítica da interpretação neoclássica do processo de modernização da agricultura brasileira, in: SANTOS, R. F. dos, Presença de vieses de mudança técnica da agricultura brasileira, São Paulo: USP/IPE, p. 39-78, 1986.

${ }^{4}$ SANTOS, M. J. dos, Rumo a um projeto alternativo de desenvolvimento rural sustentável, in: CONGRESSO BRASILEIRO DE ECONOMIA E SOCIOLOGIA RURAL, 37, 1999, Foz do Iguaçu, Anais (CD Room), 10p.
}

Raízes, Campina Grande, vol. 21, n0 01, p. 137-147, jan./jun. 2002 
Dentro deste contexto, segundo o referido autor, os agricultores mais frágeis foram excluídos do processo de produção. Ademais, com a consolidação do modo de produção capitalista, no campo brasileiro, ocorre um processo de separação do trabalhador de seus meios de produção. Estabelece-se, assim, a subjugação real do trabalho ao capital. Os trabalhadores passam a ser substituídos por máquinas e outros insumos industriais, passando a ser marginalizados e a ter suas condições de trabalho precarizadas.

Devem-se considerar, também os efeitos da modernização sobre o meio ambiente. A partir dela, ocorreu inclusive a subjugação, quase total, da agricultura ao capital. Tal subjugação consolidou-se com a implantação de um modelo altamente consumidor de energia e degradador dos recursos naturais (como o solo e a água, por exemplo). Nesses termos ${ }^{5}$ :

A atual crise agrícola também tem fortes implicações ecológicas na medida em que os esforços para intensificar a produção tiveram efeitos negativos, diretos e indiretos, sobre o meio ambiente. (...) A preocupação com a nocividade da mecanização e a utilização de insumos químicos do pacote tecnológico prevalecente para o solo, os rios, a fauna, a flora e o próprio organismo humano - particularmente em vista da necessidade de doses cada vez maiores de fertilizantes e defensivos - têm gerado uma polêmica mundial.

Assim, cabe indagar-se: com as disparidades apresentadas pelo atual modelo, no que se refere à degradação ambiental e à exclusão social, principalmente no Nordeste brasileiro, que concentra mais de $50 \%$ da população rural pobre do país, como criar um modelo de desenvolvimento rural sustentável?

Esta indagação é de fundamental importância, tendo em vista que, na visão de autores, como Santos ${ }^{6}$, a globa- lização da economia e suas transformações anteciparam o esgotamento do atual modelo agrário fazendo-se necessário, com isto, adequar as políticas públicas para a criação de um novo modelo de desenvolvimento sustentável, que deve ter, como parâmetros fundamentais, a reforma agrária e o fortalecimento da agricultura familiar. Só assim o espaço rural poderá ser revalorizado, promovendo a inclusão de milhares de excluídos, gerando reflexos para a sociedade brasileira como um todo.

Desta maneira, como forma de aprofundar este debate buscar-se-á, no tópico seguinte, tecer algumas considerações sobre a noção de desenvolvimento sustentável, com base na ampla discussão que cerca este tema.

\section{AS INCONSISTÊNCIAS DO ATUAL MODELO DE DESENVOLVIMENTO E A NOÇÃO DE DESENVOLVIMENTO SUSTENTÁVEL}

Desde a consolidação do paradigma industrial - o industrialismo - a noção de desenvolvimento ${ }^{7}$ passou a ser atrelada à produção de mercadorias em grande escala. Assim, o conceito de desenvolvimento associou-se ao de crescimento econômico. Deste modo e de acordo com Santos $^{8}$ isso permitiu que o desenvolvimento dos países fosse medido apenas pelo índice de renda per capita, desconsiderando-se as questões sociais e, principalmente, as ambientais.

É notório que tal procedimento mascara a exploração e a exclusão social, que cresceu e cresce paralelamente ao desenvolvimento. Martine ${ }^{9}$ concorda que o aumento da produção não é condição suficiente para o bem-estar geral, pois nada garante que os benefícios do crescimento serão distribuídos entre todos os setores da sociedade.

${ }^{5}$ MARTINE, G, Fases e faces da modernização agrícola brasileira. Op. Cit., p. 30.

${ }^{6}$ SANTOS, M. J. dos, Rumo a um projeto alternativo de desenvolvimento rural sustentável. Op. Cit., p. 10.

${ }^{7}$ De acordo com GUTBERLET, J, Desenvolvimento desigual: impasses para a sustentabilidade, São Paulo: Fund. Konrad Adenauer, p. 5-23, 1998, "O modelo de desenvolvimento predominante teve como inspiração filosófica o pensamento cartesiano, que estruturou a ciência moderna com o paradigma da racionalidade e da objetividade analítica. Em termos práticos, este pressuposto se traduziu no caráter mecanicista e acumulativo do sistema econômico, que coloca o crescimento de bens como base do conceito de desenvolvimento. $\mathrm{O}$ enfoque do modelo industrial de desenvolvimento, sobre o qual se estabeleceu a sociedade moderna, tem como pressuposto básico a idéia de 'progresso'. Este modelo clássico tem como fundamento a crença no conhecimento técnico-científico e o domínio da natureza, grande provedora material do crescimento".

${ }^{8}$ SANTOS, M. J. dos, Rumo a um projeto alternativo de desenvolvimento rural sustentável. Op. Cit., $10 \mathrm{p}$.

${ }^{9}$ MARTINE, G, Fases e faces da modernização agrícola brasileira. Op. Cit., p. 30. 
Ademais, cabe mencionar que, atrelado a esta noção de desenvolvimento, além da exclusão social, desconsiderouse, por muito tempo, a questão ambiental, porque os recursos naturais eram tidos com infinitos. Só que, a partir da década de 80, diferentes atores sociais (como as ONGs) passaram a questionar o atual modelo de desenvolvimento, levantando os precedentes de sua "insustentabilidade".

Com base neste contexto, passou-se a buscar alternativas para se criar um novo modelo de desenvolvimento que seja socialmente mais justo e ambientalmente mais correto, perpassando pela consideração não somente dos aspectos quantitativos, mas, acima de tudo, dos aspectos qualitativos. Para isto, torna-se necessário considerar não apenas os agregados econômicos (como PIB ou renda per capita), mas, acima de tudo, os aspectos como eqüidade social e qualidade ambiental.

Para Magalhães ${ }^{10}$ desenvolvimento sustentável é o que tem capacidade de permanecer ao longo do tempo, ou seja, é o desenvolvimento durável em todas as suas dimensões. Este, além desta dimensão global, deve incorporar as dimensões: a) econômica: relativa à capacidade de sustentação dos investimentos; b) social: no que diz respeito à capacidade de incorporar as populações marginalizadas, reduzindo os desequilíbrios sociais; c) ambiental: relativa à necessidade de conservação dos recursos naturais e da capacidade produtiva da base física; d) política: relacionada à estabilidade decisória das políticas de desenvolvimento. Para este autor, tal atitude é fundamental para permitir a incorporação do conceito de desenvolvimento sustentável aos procedimentos do processo de planejamento.

Convém mencionar que existem diferentes conceitos de desenvolvimento sustentável; contudo, no seio de todos eles apresenta-se um ponto em comum: a necessidade de se adotar um modelo de desenvolvimento que promova o crescimento econômico e não degrade o meio ambiente, numa perspectiva de longo prazo ${ }^{11}$.

Não é por outra razão que para Santos ${ }^{12}$ :

Este desenvolvimento deve privilegiar o ser humano na sua integralidade, possibilitando a construção da cidadania. As questões econômicas, portanto, têm que ser articuladas às questões sociais, culturais, políticas, ambientais e às relações sociais de gênero e raça.

Os condicionantes básicos para se alcançar este desenvolvimento sustentável perpassam não só por um caráter assistencialista, que apenas perpetua a dependência, mas, também, por políticas públicas que privilegiem e dêem condições para distribuição de renda, promovendo a eqüidade social, porque a concentração, tanto de terra como de renda, é um dos principais entraves proporcionadores de desigualdades na sociedade brasileira. Neste contexto, e se levando em consideração a realidade da sua população rural, quais as alternativas para se implantar um modelo de desenvolvimento rural que seja sustentável, tanto do ponto de vista social como ambiental?

Segundo Santos ${ }^{13}$ :

... não há desenvolvimento no meio rural sem educação, saúde, garantias previdenciárias, salários dignos, erradicação do trabalho infantil e escravo, respeito a autodeterminação dos povos indígenas e a preservação do meio ambiente. [Assim sendo] as lutas dos trabalhadores e trabalhadoras pela terra, política agrícola diferenciada, políticas sociais e direitos trabalhistas se inserem, portanto, na construção de um projeto alternativo de desenvolvimento, baseado na expansão e no fortalecimento da agricultura, em regime da economia familiar.

Esta reavaliação do processo produtivo, pouco mobiliza a sociedade predominando, ainda, a falsa idéia de expandir o consumo, sem questionar seus impactos socioambientais; no entanto, considerando-se que não será possível alcançar um desenvolvimento que seja durável, com base no modelo convencional, que é altamente excludente e devastador dos recursos naturais, faz-se urgente repensar a própria noção de desenvolvimento e adaptar as técnicas agrícolas para resolver as crises social e ambientais enfrentadas pelo Brasil hoje, não apenas em algumas regiões, mas no Brasil, como um todo.

\section{ALGUMAS CONSIDERAÇÕES SOBRE O PERFIL SOCIOECONÔMICO DA AGRICULTURA FAMILIAR NO NORDESTE BRASILEIRO}

${ }^{10}$ MAGALHÃES, A. R, Um estudo de desenvolvimento sustentável no Nordeste semi-árido, in: CAVALCANTI, C. (org.), Desenvolvimento e natureza: estudo para uma sociedade sustentável. 2. ed. São Paulo: Cortez, Recife, PE: Fund. Joaquim Nabuco, p. 417-428, 1998.

${ }^{11}$ Ver SCHETTINO, L. F. \& BRAGA, G. M. Agricultura familiar \& sustentabilidade. Vitória: ed. Do Autor, 2000, p.51-73.

${ }^{12}$ SANTOS, M. J. dos, Rumo a um projeto alternativo de desenvolvimento rural sustentável. Op. Cit., p. 2

${ }^{13}$ Cf. Id. Ibid., p.3. 
O Brasil possui 4.859 .864 estabelecimentos rurais; destes, 4.139 .369 , o que corresponde a $85,2 \%$, pertencem ao segmento familiar, e 554.501, ou seja, 11,4\%, ao segmento patronal. Cabe considerar-se que os estabelecimentos familiares ocupam apenas $30,5 \%$ da área total, enquanto os estabelecimentos patronais, embora em menor número, correspondem a $67,9 \%$ da área total, refletindo no elevado grau de concentração da terra no Brasil ${ }^{14}$.

Na região Nordeste existem 2.055.157 estabelecimentos familiares, o que representa $88,3 \%$ do total, ocupando $43,5 \%$ da área regional, produzindo $43 \%$ de todo o valor bruto da produção, mas recebendo apenas $26,8 \%$ dos financiamentos agrícolas ${ }^{15}$. Fica claro que o financiamento que se destina à agricultura é desproporcional entre os agricultores familiares e patronais, estes últimos auferindo a maior parte dos recursos.

É interessante notar-se, também, no que diz respeito ao financiamento, que as disparidades se apresentam também entre os agricultores da mesma categoria, em diferentes regiões do país. Os agricultores familiares da região Nordeste representam cerca de $50 \%$ dos estabelecimentos familiares, $32 \%$ da área, $17 \%$ do valor bruto da produção familiar do Brasil, recebendo somente $14 \%$ do financiamento total ${ }^{16}$.

Diante desta realidade, constata-se que é nesta região que se concentra a maior parte dos agricultores descapitalizados do país. Do total de estabelecimentos familiares do Nordeste, $52 \%$ foram classificados como descapitalizados, ocupando $15,1 \%$ da área total, sendo responsáveis por $8,3 \%$ de todo o valor produto da produção da região.

Assim sendo, enfatizando-se o Nordeste de forma particular, considera-se que:

A agricultura familiar é a principal geradora de postos de trabalho no meio rural. Entretanto, uma parte das pessoas ocupadas na agricultura familiar não consegue obter uma renda mínima unicamente por meio de seus estabelecimentos. Para sobreviver, muitos agricultores familiares dependem de rendas externas aos estabelecimentos agrícolas, como aposentadorias, vendas de serviços em outros estabeleci- mentos (familiares e patronais) ou atuando em atividades não-agrícolas ${ }^{17}$.

Não é por acaso que, em estudo realizado por Silva ${ }^{18}$ constatou-se que, do total de pessoas ocupadas no meio rural nordestino, no ano de 1997, cerca de um quarto exercia atividades não-agrícolas. Percebe-se, assim, a necessidade de incorporar estas atividades nas políticas públicas, para o fortalecimento do segmento familiar, tendo em vista que as unidades familiares não conseguem, por vários motivos, por meio de atividades agrícolas, unicamente, gerar rendas suficientes para a sua subsistência no campo.

\section{AGRICULTURA FAMILIAR E O SEU PAPEL PARA O DESENVOLVIMENTO SUSTENTÁVEL DO NORDESTE}

As condições atuais de sustentabilidade da região nordestina, em todas as vias, econômicas, sociais, ambientais e políticas, segundo Magalhães ${ }^{19}$ são pouco satisfatórias. Do ponto de vista econômico, a economia do interior é altamente vulnerável às variações climáticas e outros fenômenos ambientais onde, mesmo em tempos normais, não se gera renda suficiente para sustentar a população. No que diz respeito aos aspectos sociais, mostra-se com os indicadores disponíveis índices alarmantes de pobreza. Sob o aspecto ambiental, os processos de desertificação refletem as condições de uso insustentável dos solos, da vegetação, dos recursos hídricos e da biodiversidade. Percebe-se, com isto, que, globalmente, as condições de desenvolvimento atual no Nordeste não são de sustentabilidade.

Deste modo, parte dos produtores familiares da região Nordeste ainda sobrevive em função dos baixos investimentos que executa e das rendas não-agrícolas obtidas por parte de alguns membros da família, através da pluriatividade. Cabe mencionar que esta se apresenta com um caráter diverso. Ela pode atuar como uma estratégia de so-

${ }^{14}$ Convém lembrar que, os dados obtidos em INCRA/FAO, Novo retrato da agricultura familiar: o Brasil redescoberto, Op. Cit., referem-se ao Censo Agropecuário do IBGE, de 1995/1996. Assim sendo, deve-se considerar a defasagem nos mesmos ao extrapolá-los para o período atual.

${ }^{15}$ Cf. Id. Ibid.

${ }^{16}$ Cf. Id. Ibid.

${ }^{17}$ Cf. Id. Ibid., p. 52.

18 SILVA, J. G. da, O novo rural brasileiro. 2. ed. rev. Campinas, SP: UNICAMP. IE, p.1-32, 1999 (Coleção Pesquisa, 1).

${ }^{19}$ MAGALHÃES, A. R, Um estudo de desenvolvimento sustentável no Nordeste semi-árido. Op. Cif. 
brevivência ou como um elemento de modernização e de desenvolvimento, este último caso típico dos países desenvolvidos.

Considerando-se o grau de importância econômicosocial deste segmento, um conjunto de fatores justifica a escolha pelo fortalecimento da agricultura familiar, como parâmetro para o desenvolvimento sustentável no Brasil e, principalmente, no Nordeste. Para Santos ${ }^{20}$ :

A opção pela agricultura familiar se justifica pela sua capacidade de geração de emprego (da família e de outros) e renda a baixo custo de investimento. A sua capacidade de retenção da população fora dos grandes centros urbanos é um fator fundamental na construção de alternativas de desenvolvimento. Sua capacidade de produzir alimentos a menor custo e, potencialmente, com menores danos ambientais, impulsiona o crescimento de todo o entorno socioeconômico local. A agricultura [familiar] é, portanto, o principal agente propulsor do desenvolvimento comercial e, conseqüentemente, dos serviços nas pequenas e médias cidades no interior do Brasil. Basta criar incentivos à agricultura, para que se obtenha respostas rápidas nos outros setores econômicos, pelo seu efeito multiplicador. (...) É o desenvolvimento com distribuição de renda no setor rural que viabiliza e sustenta uma qualidade de vida no setor urbano.

De acordo com estas afirmações, pode-se perceber o grande papel a ser desempenhado pela agricultura familiar, no que diz respeito a um projeto de desenvolvimento sustentável. Assim sendo, as políticas públicas devem ser voltadas para o desenvolvimento das potencialidades da agricultura familiar, em conjunto com diferentes atores sociais, de modo a incluir, de forma produtiva, o grande número de produtores marginalizados pelas políticas de cunho apenas setorial.

Daí a necessidade de se buscar alternativas para fortalecer estes segmentos, para a consolidação de um projeto alternativo de desenvolvimento, que deve ter, como característica básica, a eliminação da pobreza rural, garantindo condições de vida digna para as populações locais. Para isto, o ponto principal é identificar as potencialidades locais, para definir as políticas públicas de acordo com cada realidade, privilegiando tanto as atividades agrícolas como as não-agrícolas.

Neste contexto e no que se refere às alternativas para a agricultura familiar, Martine ${ }^{21}$ enfatiza que existe a possibilidade de que novas tecnologias, como a biotecnologia, possam ser adequadas a esta categoria. Isto será favorável principalmente em regiões como o semi-árido nordestino.

A questão que se coloca é: a quem estas novas tecnologias irão beneficiar? A este respeito, Olalde e Silveira ${ }^{22}$ esclarecem que é necessário “pensar o quanto o elevado grau de concentração de poder econômico e da informação retida nas grandes corporações põe um limite a atividades de pesquisa que, por sua natureza de impacto no espaço econômico, deveriam ser conduzidas de forma descentralizada”. A questão é limitar o poder dos grupos de interesse também neste segmento, porque é notório, dependendo do rumo tomado, que a biotecnologia poderá ser utilizada como mecanismo para resolver as disparidades socioeconômicas, como poderá, também, agravá-las.

Neste sentido, torna-se necessário definir o papel do Estado, da empresa privada e das universidades, tendo em mente não apenas aspectos técnicos, mas, acima de tudo, sociais e ambientais. No que se refere a estes aspectos e enfocando o lado social da biotecnologia, Castro e Marti$n e^{23}$ concordam que ela será tão boa e tão justa de acordo com o uso que lhe for dado. Neste sentido, a biotecnologia tanto pode agravar como atenuar as profundas desigualdades que existem entre as diferentes regiões do país. Sendo assim, os autores alertam para a necessidade de se saber a quem a biotecnologia vai beneficiar; somente deste modo possíveis tendências poderão ser estabelecidas.

De acordo com Belik ${ }^{24}$ ainda existe espaço para a intervenção do Estado na condução das políticas para a agropecuária, só que o formato da atuação e a elaboração de novos instrumentos de desenvolvimento devem ser repensados.

\footnotetext{
${ }^{20}$ SANTOS, M. J. dos, Rumo a um projeto alternativo de desenvolvimento rural sustentável. Op. Cit., p. 4.

${ }^{21}$ MARTINE, G, Fases e faces da modernização agrícola brasileira. Op. Cit.

22 OLALDE, A. R.; SILVEIRA, J. M. F. J. da, O desenvolvimento da biotecnologia aplicada ao setor agroalimentar e a constituição de sistemas em "rede", in: CONGRESSO BRASILEIRO DE ECONOMIA E SOCIOLOGIA RURAL, 37, 1999. Foz do Iguaçu. Anais (CD Room), p. 3.

${ }^{23}$ CASTRO, C. de M; MARTINE, G, Introdução: o que o Brasil tem a ver com a biotecnologia? In: MARTINE, G.; CASTRO, C. de M. (orgs.), Biotecnologia e sociedade: o caso brasileiro. Campinas: ALMED, p. 11-19, 1985.

${ }^{24}$ BELIK, W., Estado, grupos de interesse e formulação de políticas para a agropecuária brasileira. Op. Cit., p. $9-34$.
} 
Outros autores também fizeram referência a esta questão; no entanto, segundo Waquil25 "em qualquer caso, a agricultura familiar requer condições (políticas, financeiras, sócio-culturais, organizacionais e institucionais) para promover os ajustamentos necessários”.

De modo geral, a expansão da agricultura familiar depende de uma política agrária abrangente, que permita o acesso à terra a todos os trabalhadores sem terra, ou com terra insuficiente, para assegurar, com isto, as condições necessárias à distribuição de renda, sustentabilidade e competitividade deste segmento, tão importante da agricultura brasileira. Para tanto, faz-se necessário que as políticas publicas que visam ao fortalecimento da agricultura familiar, onde se pode destacar o PRONAF, não apenas priorizem a disponibilização de recursos, mas, também, busquem fornecer conhecimentos para promover a independência dos agricultores familiares, tendo como base, por exemplo, o planejamento local.

\section{A QUESTÃO LOCAL E OS NOVOS DESAFIOS}

Numa época em que se discute o problema da fome e da miséria no Brasil, torna-se imprescindível atentar para o Nordeste, pois é nesta região que se concentra mais da metade da pobreza rural e a simples constatação deste fato já justifica a necessidade de se buscar alternativas para a construção de um novo modelo de desenvolvimento agrícola para a região. Se assim for, quais as premissas para a construção desse novo modelo que deve priorizar, acima de tudo, a redução da pobreza rural?

Como já visto, a agricultura familiar desempenha papel socioeconômico fundamental, em todo Brasil, ressaltando-se que o problema reside no seu histórico abandono pelas políticas públicas, principalmente no Nordeste. É bom lembrar que, para se levar avante qualquer programa de desenvolvimento é oportuna a forte presença de uma política de financiamento das atividades produtivas. Muitos programas governamentais já foram desenvolvidos com este fim; a maioria, no entanto, ficou a desejar, por não contemplar os agricultores familiares, enclausurados na sua condição de pauperizados.
Uma pretensa tentativa de mudança tomou forma em 1996, com a criação do Programa Nacional de Fortalecimento da Agricultura Familiar (PRONAF); contudo, de forma semelhante aos programas anteriores, a região Nordeste, mais uma vez, ficou marginalizada ${ }^{26}$, cujo descaso provoca um conjunto de distorções neste segmento tão importante da economia nacional. Tais distorções ocorrem: na etapa da produção propriamente dita; na obtenção e utilização de insumos e equipamentos; na administração das propriedades; no transporte, conservação e armazenagem das colheitas e, principalmente, na comercialização dos excedentes, apropriada, na maioria das vezes, pelos atravessadores, através da compra a preços abaixo do valor que deveria prevalecer.

Devido, principalmente, a estas “ineficiências” é que a grande maioria dos agricultores familiares do Nordeste, além de gerar um excedente muito pequeno, não consegue acumular nem competir no mercado, relegando-se à condição de produtores apenas para subsistência.

As conseqüências de tal abandono são conhecidas. Pode-se citar, a título de exemplo, a precarização das condições de vida no campo, que ocasiona o êxodo rural, um dos grandes problemas a serem solucionados no Brasil. Como as cidades de destino das migrações não têm mais capacidade de absorver, produtivamente, os migrantes, surge a necessidade de se incentivar a criação de condições econômicas, sociais e ambientais favoráveis para que os agricultores e seus familiares permaneçam no campo.

As diferenças entre o rural e o urbano, no que diz respeito a alguns bens e serviços fundamentais (saúde, educação e infra-estrutura) são ainda muito grandes. Estas disparidades assumem um peso significativo nas diferentes regiões do país; no entanto, é da comparação entre a realidade urbana e rural, no Brasil e no Nordeste, que se pode visualizar melhor este quadro (Tabela 1).

Pode-se perceber, na Tabela 1, o "déficit social" para com o rural brasileiro e, em especial, com o nordestino. No Brasil, apenas 12\% dos domicílios rurais, em 1996, tinham acesso a coleta de lixo; mais da metade da população rural não tinha acesso a filtro de água e quase um terço da população era analfabeta; considerando-se o espaço rural nordestino, esses números assumem um peso mai-

${ }^{25}$ WAQUIL, P. D. Produção agrícola familiar no Brasil no contexto da integração regional. In: CONGRESSO BRASILEIRO DE ECONOMIA E SOCIOLOGIA RURAL, 37, 1999, Foz do Iguaçu. Anais (CD Room), 10p.

${ }^{26}$ Dos recursos alocados pelo PRONAF, entre os anos 1995 e 1998, 61,7\% foram carreados para a região Sul e apenas 18,4\%, foram destinados ao Nordeste (Democracia Viva, 1999 apud Alves, s/d). 
or. Apenas 7,3\% dos domicílios rurais permanentes tinham acesso a coleta de lixo, em 1996; os demais indicadores confirmam a precariedade do quadro social no Nordeste, destacando-se o elevadíssimo número de analfabetos de 10 anos ou mais - nada menos que $42,3 \%$ da população residente no meio rural.

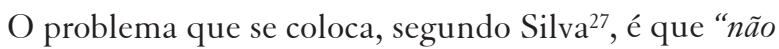
existem programas específicos para o meio rural destinados a estreitar essa lacuna com os residentes urbanos, no que diz respeito ao acesso aos bens básicos." Como conseqüência desta realidade, o referido autor ainda comenta que não é de estranhar que as pessoas busquem se deslocar, no caso do Nordeste, para os pequenos municípios do interior, a fim de conquistarem a cidadania, através do acesso, pelo menos, aos bens básicos, mas ocorre que essa trajetória não é tão simples, muito menos implica na solução dos problemas do migrante. Geralmente, as pequenas e médias cidades do interior nordestino não têm condições de recepcionar os migrantes, no sentido de lhes ofertar o que procuram - melhores condições de vida. Dá-se, com isto, um processo de favelização local, de tal forma que, não encontrando emprego e nem condições infra-estruturais adequadas, o trabalhador migra novamente, desta vez para os grandes centros urbanos da região Centro-Sul do país.

Tabela 1: Domicílios particulares permanentes que têm acesso a alguns serviços e bens básicos e taxa de analfabetismo (\%): Brasil e Nordeste, 1996.

\begin{tabular}{|c|c|c|c|c|}
\hline \multirow{2}{*}{ Item/Bem } & \multicolumn{2}{|c|}{ Brasil } & \multicolumn{2}{|c|}{ Nordeste } \\
\hline & Urbano & Rural & Urbano & Rural \\
\hline Esgotamento sanitário & 96,1 & 62,0 & 88,4 & 39,7 \\
\hline Coleta de lixo & 87,5 & 12,0 & 72,9 & 7,3 \\
\hline Iluminação elétrica & 98,7 & 66,9 & 97,4 & 52,3 \\
\hline Telefone & 30,3 & 4,5 & 20,0 & 2,2 \\
\hline Filtro de água & 61,5 & 43,3 & 64,0 & 41,8 \\
\hline Geladeira & 86,4 & 43,2 & 69,5 & 22,0 \\
\hline Rádio & 91,9 & 83,9 & 86,5 & 78,1 \\
\hline Televisão & 91,3 & 54,3 & 83,7 & 38,5 \\
\hline Analfabetos 10 anos ou + & 10,0 & 29,3 & 19,2 & 42,3 \\
\hline
\end{tabular}

Visto o problema desse ângulo, o que fazer? A tese aqui defendida é que se faz necessário, para que o agricultor possa ter acesso à cidadania no campo, criar políticas de desenvolvimento local que priorizem, acima de tudo, a eliminação da pobreza rural. Em outras palavras, faz-se necessário um conjunto de medidas voltadas para a realidade local, onde os agricultores tenham condições de se tornar menos dependentes dos recursos públicos e, acima de tudo, sejam mais eficientes na utilização dos recursos disponíveis. Segundo Campanhola e Silva ${ }^{28}$,

o desenvolvimento local deve ser, acima de tudo, um processo de reconstrução social, que deve se dar 'de baixo para cima', com a participação efetiva dos atores sociais.

O fortalecimento das políticas locais de desenvolvimento, de acordo com Gutberlet ${ }^{29}$,

coloca-se como possibilidade real de enfrentamento da desigualdade, já que permite uma participação maior dos cidadãos nas decisões públicas. Para este autor, é no nível local que as políticas públicas podem reverter, de curto a médio prazo, estruturas que prejudicam e excluem grande parte da população.

Vale frisar ainda que, encarado desta forma, o projeto abrangerá a economia como um todo. Por que tal afirmação? Em virtude da não capacidade das cidades de gerarem empregos e renda para toda a população, promovendo grandes índices de pobreza e exclusão social. A partir disso, conclui-se que não se pode pensar em processo de desenvolvimento geral para o país sem o fortalecimento da agricultura, gerando condições de emprego e renda no meio rural. Ademais, é mais barato gerar e/ou manter empregos agrícolas do que urbanos.

Este aspecto macroeconômico deve ser considerado como meio de integrar diferentes atores sociais (rurais e urbanos) nesta luta pela construção de um novo modelo de desenvolvimento para o Brasil.

Quais devem ser os pontos norteadores dessas políticas? Segundo Santos ${ }^{30}$,

\footnotetext{
${ }^{27}$ SILVA, J. G. da, o novo rural brasileiro, Op. Cit., p. 105.

${ }^{28}$ CAMPANHOLA, C.; SILVA, J. G. da, Diretrizes de políticas públicas para o novo rural brasileiro: incorporando a nocão de desenvolvimento local. In: CONGRESSO BRASILEIRO DE ECONOMIA E SOCIOLOGIA RURAL, 37, 1999, Foz do Iguaçu. Anais (CD Room), p. 4.

${ }^{29}$ GUTBERLET, J, Desenvolvimento desigual: impasses para a sustentabilidade, Op. Cit., p. 21.

${ }^{30}$ SANTOS, M. J. dos, Rumo a um projeto alternativo de desenvolvimento rural sustentável. Op. Cit., p. 6.
} 
educação, saúde, lazer, previdência e assistência social, formação profissional, pesquisa e assistência técnica são elementos estruturais de qualquer proposta de desenvolvimento.

Neste sentido, o que é necessário para a implantação do desenvolvimento local? Campanhola e Silva ${ }^{31}$ concordam que:

Qualquer iniciativa de planejamento local deve-se iniciar pela caracterização socioeconômica e ambiental dos recursos disponíveis e pelo zoneamento territorial, de modo a que se tenha uma ocupação territorial organizada a níveis locais e regionais, respeitando-se os princípios do desenvolvimento sustentável.

Para tanto e na opinião destes autores, os instrumentos fundamentais de apoio às políticas de desenvolvimento rural são três: educação, pesquisa associada à extensão rural e associativismo. Assim sendo, conforme Abramovay $^{32}$, a idéia de desenvolvimento local procura colocar ênfase em mecanismos institucionais específicos capazes de mobilizar as energias produtivas que o funcionamento dos mercados, por si só, acaba por inibir. Em outras palavras, estas afirmações corroboram a idéia de que o desenvolvimento não é um processo natural e/ou espontâneo; pelo contrário, ele é construído de acordo com a capacidade dos atores de estabelecer relações organizadas - mercantis e não mercantis - que favoreçam não apenas os aspectos econômicos, mas também a pressão coletiva pela existência e melhoramento dos bens públicos e administrações que dinamizam a vida regional e local.

Para que sejam atingidas tais metas, um dos principais obstáculos a ser removido é a incompatibilidade do ensino praticado no meio rural, caracterizada pela separação total entre o ensino básico e a formação profissional dos agricultores. Tal realidade atinge, principalmente, os jovens rurais que, na ausência de alternativas que os profissionalizem e os motivem a organizar suas vidas nas regiões de origem, são obrigados a migrar para outras regiões do país, comprometendo o processo sucessório na agricultura.

Deste modo, faz-se imperativo reformular os currículos das escolas primárias rurais, para que os jovens rurais possam ter a oportunidade de se tornarem cidadãos independentes e comprometidos com a transformação de suas realidades. Para tanto, é necessário um conjunto de mudanças a serem implantadas, onde se pode destacar: i) adequar os conteúdos dos programas de ensino; ii) elaborar novos materiais e textos didáticos; iii) adotar novos métodos de ensino e iv) recapacitar os professores para esta nova realidade. Essas reformulações são importantes na medida em que se preconiza a construção de um modelo de desenvolvimento baseado nos preceitos da sustentabilidade, como se mencionou no tópico anterior. Neste sentido, faz-se necessário que os agricultores adotem uma nova postura, que façam face às exigências desse novo paradigma de organização da produção, tornando-se mais eficientes e competitivos.

Como protagonista deste processo, deve-se destacar o novo papel da extensão rural, na difusão de técnicas e conhecimentos que proporcionem maior organização e eficiência aos produtores, com vistas à expansão e ao fortalecimento da agricultura familiar. A ação da moderna extensão rural deverá ser essencialmente emancipadora e não perpetuadora de dependências. Isto indica que, para desenvolver a agricultura familiar, é necessário, primeiramente, formar as famílias rurais para que tenham novos conhecimentos e, especialmente, para que adotem novas atitudes como, por exemplo, ampliar a prática do associativismo, que é um dos requisitos fundamentais para fortalecer a agricultura familiar a nível local, com uso de novas técnicas de produção que sejam adaptadas à realidade local, ao mesmo tempo que proporcionem aos agricultores maiores condições para competir no mercado, superando suas deficiências, tanto de terra como de capital.

Compartilhando a mesma linha de interpretação, San$\operatorname{tos}^{33}$ comenta que

as ações de capacitação para o desenvolvimento local devem ser a base para este programa, contemplando a formulação e o acompanhamento de planos municipais e regionais de desenvolvimento, que devem levar em conta a diversidade e a complexidade dos interesses.

Com isto, percebe-se a importância fundamental das comunidades locais para a realização deste projeto. Daí a

${ }^{31}$ CAMPANHOLA, C.; SILVA, J.G. da, Diretrizes de políticas públicas para o novo rural brasileiro: incorporando a noção de desenvolvimento local, Op. Cit., p. 5.

32 ABRAMOVAY, R. Desenvolvimento rural territorial e capital social. In: SABOURIN, E.P. \& TEIXEIRA, O. A. Planejamento e desenvolvimento dos territórios rurais: conceitos, controvérsias e experiências. Brasília: Embrapa Informação Tecnológica, 2001 (no prelo).

${ }^{33}$ SANTOS, M. J. dos, Rumo a um projeto alternativo de desenvolvimento rural sustentável. Op. Cit., p. 9. 
importância dos órgãos de extensão, das ONGs e dos órgãos públicos, principalmente das escolas, neste processo.

É fundamental destacar-se, ainda, segundo Flores ${ }^{34}$ que, a fim de se buscar um novo modelo de desenvolvimento para o campo, deve-se considerar que é possível, com estratégias de organização da produção e do mercado, ter produção economicamente viável em pequenas propriedades. Para tanto, deve-se buscar, como alternativa para o desenvolvimento, não apenas o incentivo a atividades agrícolas; pelo contrário, o meio rural cada vez mais deve ser encarado em função de sua multifuncionalidade, de tal forma que as estratégias de desenvolvimento rural incorporem tanto as atividades agrícolas como as não-agrícolas. Isto implica encarar o desenvolvimento numa perspectiva territorial e não apenas setorial e, assim, haverá um alargamento das possibilidades de geração de renda além das atividades estritamente agrícolas, contribuindo para a melhoria do nível de vida da população rural.

Em suma, para se responder à necessidade de se implantar um novo modelo de desenvolvimento que atenda aos anseios das gerações atuais, sem comprometer as futuras, faz-se necessário distribuir o poder, garantindo a participação local. Além do mais, deve-se contemplar, em toda e qualquer estratégia de desenvolvimento, a busca pela melhoria da qualidade de vida da população residente no meio rural. Para tanto, é conveniente o desenvolvimento de uma ação consciente e deliberada das organizações governamentais e não-governamentais, bem como de toda a sociedade, que possibilite aos atores locais diagnosticarem os seus problemas e serem os protagonistas na solução dos mesmos. A perspectiva setorial do desenvolvimento deve ser substituída por uma abordagem territorial, a fim de serem ampliadas as possibilidades de geração de postos de trabalho e renda no meio rural nordestino.

\section{CONSIDERAÇÕES FINAIS}

Considerando-se que a modernização ocorreu de forma desigual no tempo e no espaço, desenvolvendo-se de forma conservadora, privilegiando grandes proprietários, preponderantemente nas regiões mais desenvolvidas, marginalizando as demais, foi que um amplo debate foi travado no meio acadêmico.
As marcas de esgotamento do atual modelo de desenvolvimento são latentes na região Nordeste, onde se concentra mais da metade da pobreza rural do país e em que a maior parte da população vive em pequenas propriedades, auferindo rendas baixíssimas, sobrevivendo graças a rendas não-agrícolas, oriundas principalmente das transferências públicas, na forma de pensão e aposentadoria. As disparidades econômicas, sociais e ambientais comprovam isso.

Desde meados da década de 90, com o processo de descentralização das políticas públicas, um conjunto de autores está desenvolvendo pesquisas, buscando criar alternativas para resolver ou pelo menos amenizar as disparidades regionais. Neste sentido, é sugerido que as políticas públicas para o meio rural devem ter, como prioridade, a eliminação da pobreza, seja ela de cunho agrícola ou não-agrícola. Para tanto, far-se-á necessário realizar amplos investimentos em educação e apoio à extensão rural, como meio de se adaptar e moldar os agricultores para que eles mesmos possam diagnosticar e transformar suas realidades.

Entende-se que é através da cooperação entre diferentes segmentos da sociedade, não através de políticas elaboradas "de cima para baixo" mas, sim, "de baixo para cima”, priorizando as potencialidades locais, prevalecendo o associativismo e a cooperação, onde podem estar as saídas para os vários problemas (econômicos, sociais, ambientais, políticos e culturais, dentre outros) que caracterizam o espaço rural brasileiro, de modo geral, e o espaço rural nordestino, de modo particular.

\section{REFERÊNCIAS BIBLIOGRÁFICAS}

ABRAMOVAY, R. Desenvolvimento rural territorial e capital social. In: SABOURIN, E. P. \& TEIXEIRA, O. A. Planejamento e desenvolvimento dos territórios rurais: conceitos, controvérsias e experiências. Brasília: Embrapa Informação Tecnológica, 2001 (no prelo).

ALVES, M. O. Desempenho dos programas públicos de geração de emprego e renda: a avaliação do IBASE. BNB/ ETENE, s/d. 12p. 
BELIK, W. Estado, grupos de interesse e formulação de políticas para a agropecuária brasileira. Rev. Econ. Sociol. Rural. v. 36, $\mathrm{n}^{\circ} .1$, jan/mar. 1998.

CAMPANHOLA, C. SILVA, J. G. da. Diretrizes de políticas públicas para o novo rural brasileiro: incorporando a noção de desenvolvimento local. In: CONGRESSO BRASILEIRO DE ECONOMIA E SOCIOLOGIA RURAL, 37, 1999, Foz do Iguaçu. Anais (CD Room), 27p.

CASTRO, C. de M. e MARTINE, G. Introdução: o que o Brasil tem a ver com a biotecnologia? In: Biotecnologia e sociedade: o caso brasileiro. Campinas: ALMED, 1985.

FLORES, M. Desenvolvimento local: um caminho para o novo mundo rural. In: AGUIAR, D. R. D. de \& PINHO, J. B. (eds.). Agronegócio brasileiro: desafios e perspectivas. Brasília: Sociedade Brasileira de Economia e Sociologia Rural - SOBER, v. 1, 1998. p. 187-194.

GUTBERLET, J. Desenvolvimento desigual: impasses para a sustentabilidade. São Paulo: Fund. Konrad Adenauer, 1998.

INCRA/FAO. Novo retrato da agricultura familiar: o Brasil redescoberto. Brasília, 2000.

MAGALHÃES, A. R. Um estudo de desenvolvimento sustentável no Nordeste semi-árido. In: CAVALCANTI, C. (Org.) Desenvolvimento e natureza: estudo para uma sociedade sustentável. 2. ed. São Paulo: Cortez, Recife, PE: Fund. Joaquim Nbuco, 1998.

MARTINE, G. Fases e faces da modernização agrícola brasileira. Planejamento e Políticas Públicas, $n^{\circ} .3$, jun. 1990.

OLALDE, A. R. e SILVEIRA, J. M. F. J. da. O desenvolvimento da biotecnologia aplicada ao setor agro-alimentar e a constituição de sistemas em "rede". In: CONGRESSO BRASILEIRO DE ECONOMIA E SOCIOLOGIA RURAL, 37, 1999, Foz do Iguaçu. Anais (CD Room), 10p.

SANTOS, M. J. dos. Rumo a um projeto alternativo de desenvolvimento rural sustentável. In: CONGRESSO BRASILEIRO DE ECONOMIA E SOCIOLOGIA RURAL, 37, 1999, Foz do Iguaçu. Anais (CD Room), 10p.
SANTOS, R. F. dos. Análise crítica da interpretação neoclássica do processo de modernização brasileira. In: Presença de vieses de mudança técnica da agricultura brasileira. São Paulo, USP/IPE, 1986.

SILVA, J. G. da. O novo rural brasileiro. 2. ed. rev. Campinas, SP: UNICAMP. IE, 1999. (Coleção Pesquisa, 1).

WAQUIL, P. D. Produção agrícola familiar no Brasil no contexto da integração regional. In: CONGRESSO BRASILEIRO DE ECONOMIA E SOCIOLOGIA RURAL, 37, 1999, Foz do Iguaçu. Anais (CD Room), 10p. 